\title{
Belphégor
}

\section{L'écho espagnol du roman populaire français (1850-2000). L'exemple de Paul Féval et de George Sand}

\author{
Àngels Santa and Carme Figuerola
}

\section{(2) OpenEdition \\ Journals}

Electronic version

URL: https://journals.openedition.org/belphegor/2516

DOI: $10.4000 /$ belphegor.2516

ISSN: 1499-7185

Publisher

LPCM

\section{Electronic reference}

Àngels Santa and Carme Figuerola, "L'écho espagnol du roman populaire français (1850-2000). L'exemple de Paul Féval et de George Sand", Belphégor [Online], 18-1 | 2020, Online since 04 March 2020, connection on 29 June 2021. URL: http://journals.openedition.org/belphegor/2516 ; DOI: https:// doi.org/10.4000/belphegor.2516

This text was automatically generated on 29 June 2021.

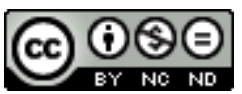

Belphégor est mis à disposition selon les termes de la Licence Creative Commons Attribution - Pas d'Utilisation Commerciale - Pas de Modification 4.0 International. 


\title{
L'écho espagnol du roman populaire français (1850-2000). L'exemple de Paul Féval et de George Sand
}

\author{
Àngels Santa and Carme Figuerola
}

\section{Introduction}

1 Au XIXe siècle l'engouement du public espagnol pour des ouvrages étrangers se faisait ressentir déjà dans la métaphore de "nation traduite » à laquelle recourait Mesonero Romanos en 1843 pour désigner l'Espagne. Aussi bien dans les collections parues chez des éditeurs que dans celles publiées par la presse, les auteurs étrangers voisinent avec les rares autochtones par le biais de traductions qui souvent dépassent la "simple» version et réalisent des transferts manifestes d'acculturation. Les données fournies par Jean-François Botrel ${ }^{1}$ le montrent clairement : $80 \%$ des romans publiés en feuilleton dans la presse sont des traductions et la source de ces traductions est aussi pour $80 \%$ d'entre elles le français. Et il précise encore :

Entre 1878 et 1891 pour les publications en livre relevant du genre narratif au sens large, pratiquement la moitié (49\%) des 1749 titres sont des traductions. En 1907, sur les 358 romans répertoriés dans Bibliografía Española, au moins 216 (60\%) sont des traductions et en 1911, cette proportion est de $30 \%{ }^{2}$

Ce monde est dominé par l'ailleurs et pour lutter contre cette domination il est nécessaire d'utiliser toute une série de moyens qui vont en nuancer la portée. Les Espagnols vont systématiquement hispaniser les textes, en essayant de les rendre autochtones dans la mesure du possible, en faisant oublier leurs origines. En outre, les agents de la médiation culturelle comme les traducteurs, les adaptateurs, les illustrateurs, les éditeurs auront un rôle efficace et décisif et vont fournir une image spécifique du texte source, parfois très éloignée de l'image première. Les auteurs désirent forger une littérature nationale dont les caractéristiques ne seront pas importées, comme il est arrivé pendant longtemps, mais tout à fait originales. La lutte entre importation et originalité demeure vivante tout au long du XXe siècle, même si 
les auteurs espagnols gagnent chaque fois plus de terrain. De la même manière les modèles culturels se déplacent et l'influence française s'efface lentement pour céder la place à l'influence anglaise. Cependant le roman populaire survit et se renouvelle via de nouvelles traductions et de nouveaux transferts.

Parmi les auteurs traduits, le panorama littéraire espagnol fait une grande place aux feuilletons français. Les grands noms de Dumas, Féval ou Sue deviennent bientôt connus des lecteurs espagnols attentifs aux nouveautés. À ces noms s'en ajoutent d'autres comme ceux de George Sand, de Lamartine ou de Stendhal, car ce n'est que plus tard que ces écrivains feront figure de classiques.

Bien que le phénomène d'importation de romans étrangers soit relativement bien connu ${ }^{3}$, cet article a pour but de rendre une étude détaillée de deux écrivains de grande fortune auprès des lecteurs espagnols, dont le sort a varié au fil du temps, mais qui permettent de mesurer la portée du roman populaire en Espagne et son évolution : Paul Féval et George Sand.

\section{Paul Féval}

5 Paul Féval a été connu en Espagne pendant longtemps sous le nom de Pablo Féval avant de redevenir Paul Féval de nos jours. Au XIXe siècle le prénom de la plupart des auteurs traduits est hispanisé pour les rendre plus proches et masquer leur origine étrangère. Paul Féval a été largement traduit en Espagne, sa bibliographie espagnole est très abondante; pour rendre cette étude plus abordable nous avons décidé de nous intéresser uniquement à quelques titres significatifs qui couvrent l'ensemble de son œuvre.

Il s'agit de : Les Mystères de Londres, 1843-1844; Le Fils du diable, 1846 ; La Duchesse de Nemours (Frère Tranquille), 1851-1853 ; Le Bossu, 1857 ; Le Capitaine Fantôme, 1861 ; Les Habits Noirs, 1863 et La Ville Vampire, 1875.

7 Nous avons utilisé pour établir les éditions les catalogues de la Bibliothèque Nationale de Madrid, de la Bibliothèque de Catalogne de Barcelone, ainsi que le Manual del librero hispano-americano par Antoine Palau et le Catalogue de la Bibliothèque Municipale de Rennes Paul Féval 1816-1887 où Jean-François Botrel publia l'article «Editions de Paul Féval en Espagnol ».

\section{Les Mystères de Londres}

Nous n'avons pas considéré les traductions antérieures à 1850, date fixée pour commencer notre étude. Les traductions du XIXe siècle n'offrent pas un intérêt particulier. L'une est réalisée en Amérique Latine, à Mexico et l'autre à Valence. Malgré la popularité des mystères qui parcourent notre pays, ceux de Féval ne semblent pas avoir éveillé un intérêt spécial. Sans doute étaient-ils occultés par Les Mystères de Paris d'Eugène Sue qui eurent un grand succès ${ }^{4}$. Cependant les traductions antérieures à 1850 connurent une vingtaine d'éditions, surtout en Amérique Latine. Ils vont avoir une meilleure fortune à partir du dernier tiers du XXe siècle. Nous y trouvons deux traductions très intéressantes, dans deux maisons d'édition spécialisées dans le genre fantastique, Taber, située à Barcelone, et Celeste Éditions, située à Madrid. 
9 Cette dernière publie l'œuvre de Féval dans une collection intitulée «Infernaliana » en prenant soin d'expliquer l'origine du nom dans la jaquette: «En 1822, el escritor y bibliófilo Charles Nodier publicó su colección de "anécdotas, narraciones y cuentos sobre aparecidos, espectros, demonios y vampiros » y la tituló Infernaliana $»^{5}$. Dans les deux cas, nous avons affaire à des traducteurs d'exception. Chez Taber, Johanna Givanel se chargea de la traduction et chez Céleste Editions ce fut Gregorio Cantera qui assura en même temps un paratexte important : une introduction et des notes.

Johanna Givanel (1907-1989), est née à Barcelone où elle étudia à l'école française Ferdinand de Lesseps Elle se maria en 1937 avec le journaliste Joaquim Ventalló. De retour à Barcelone elle travailla comme traductrice, surtout du français mais aussi de l'anglais et de l'italien. Les langues d'arrivée furent aussi bien le catalan que le castillan. Elle travailla dans les meilleures maisons d'édition de Barcelone ; parmi ses traductions $\mathrm{du}$ français nous pouvons signaler, à part Les Mystères de Londres dont il est question ici, César Birotteau de Balzac (1962), Hugues-le-loup d'Erckmann Chatrian (1969) ou La Part maudite de Georges Bataille (1974).

11 Gregorio Cantera est, à son tour, un traducteur reconnu (il a notamment traduit Alexandre Dumas), qui nous offre une version soignée accompagnée d'une introduction à la vie et à l'œuvre de Féval et des notes qui aident le lecteur à comprendre le texte.

12 Nous pouvons expliquer ces deux traductions à cause de l'engouement pour le fantastique qui se développa à la fin du XXe siècle.

\section{Le Fils du diable}

13 À peine quelques mois après sa parution en France, ce roman connut plusieurs traductions en Espagne qui se renouvelèrent pendant la deuxième moitié du XIXe siècle. Souvent les traducteurs ne sont pas mentionnés ou ils signent avec des initiales, ce qui ne permet pas de les identifier aisément. Il faut surtout attirer l'attention sur la traduction de Victor Balaguer et Francisco José Orellana, éditée pour la première fois en 1847 et reprise en 1871. Il s'agit là de deux personnages d'exception.

14 Victor Balaguer (1824-1901) est né à Barcelone. Il va plonger pleinement dans le mouvement romantique. Jeune homme, il s'inscrit dans le courant libéral, à côté du duc de Rivas, de José de Espronceda et, surtout, de José Zorilla. Balaguer lit passionnément ces auteurs, mais il y ajoute les traductions des romantiques européens. À un moment donné, il affirmera que les romans de Walter Scott ont constitué «sa première nourriture spirituelle.» À cet auteur-là, il faut ajouter Byron, Hugo et Dumas. Avec Dumas, Balaguer maintient un rapport extraordinaire, car il devient son adaptateur et son traducteur privilégié en langue espagnole pendant la deuxième moitié du XIXe siècle $^{6}$. En 1845, Victor Balaguer décide d'abandonner son foyer barcelonais pour se rendre à la capitale, à Madrid. Sa rencontre avec l'éditeur Ayguals de Izco est particulièrement intéressante ; il le charge de traduire quelques romantiques français, parmi lesquels il faut remarquer Eugène Sue avec son œuvre Arthur ${ }^{7}$. Les rapports avec Ayguals furent sans doute très fructueux, car il était, en plus d'éditeur, auteur de théâtre et romancier; son romantisme était teinté d'un lourd contenu social. Il dirigeait, à l'époque, à Madrid une Société Littéraire qui organisait diverses activités culturelles. Balaguer a la chance de pouvoir y participer. Malgré cela, le séjour à Madrid n'est pas aussi positif qu'on pouvait l'espérer; c'est pourquoi il décide de retourner à Barcelone. 

pendant le voyage précédent. Un jour, il se trouve au Café Suizo pour y rencontrer un ami; un client entre qui prend place à une autre table. Il s'agit d'Alexandre Dumas. ${ }^{8}$ Vers la mi-octobre 1847 il revient à Barcelone. Parmi les multiples activités développées par Balaguer se trouve celle de traducteur. Il l'exerce à partir des années 40 et elle devient l'une de ses tâches essentielles, qu'il faut considérer conjointement à celle d'adaptateur. Dans de nombreuses occasions il travaille en collaboration avec d'autres auteurs ou en parallèle avec eux. Au début des années quarante, il fait la connaissance de Lluís Cutchet, qui réalisa quelques traductions de Victor Hugo, tandis que Balaguer traduisait Alexandre Dumas. Il est significatif que tous les deux s'intéressent aux romantiques libéraux français9. Anicet-Bourgeois, sont ses auteurs préférés dans ce domaine. Son activité comme traducteur atteint son sommet entre 1846 et 1850 . Avant et après on trouve très peu de traductions. Dumas est son auteur préféré et avec lui, Sue, quoiqu'il ait traduit d'autres auteurs $^{10}$. En 1848 il publie la traduction de La prima donna de George Sand ${ }^{11}$. Avec Francisco José Orellana il réalise en 1847 la traduction de Le Fils du diable, comme nous l'avons déjà signalé. En 1849 ils continuent à collaborer comme rédacteurs à $\mathrm{El}$ Bien Público, où ils ont publié ensemble une autre traduction, celle du roman de Charles Félix Henri Rabou, El Gabinete negro ${ }^{12}$.

17 Plus tard, les intérêts de Victor Balaguer le mèneront vers d'autres chemins. Il deviendra un politicien d'un grand prestige et se consacrera à son œuvre, aussi bien comme poète que comme romancier.

18 Francisco José Orellana (1820-1891) est un homme à multiples facettes: écrivain, économiste, historien, éditeur et journaliste. Sa tâche comme traducteur se borne à la traduction de quelques romans français, toujours en collaboration avec Victor Balaguer, dont nous avons déjà mentionné les plus significatifs. Il faut ajouter sa traduction d'Étienne Cabet, représentant du socialisme utopique. Comme romancier, il a écrit des romans historiques, des romans sentimentaux et des romans feuilletons. Parmi ses titres, on trouve: Luzdel Alba (Lumière de l'aube) et Mundo, dinero y mujer (Monde, argent et femme). La critique le considère comme un romancier médiocre, même s'il a acquis une certaine renommée à son époque.

19 Le Fils du diable connaît au XXe siècle une certaine notoriété grâce aux traductions parues chez Ramon Sopena à Barcelone et chez Saturnino Calleja à Madrid. Les deux éditeurs ont beaucoup fait pour le roman populaire en publiant les auteurs les plus représentatifs comme le montre leur catalogue.

La maison d'édition Ramon Sopena fut créée en 1894. Tout au long du XXe siècle elle se développa rapidement et eut même un siège à Madrid. Elle fit faillite en 2004. Elle cultiva deux lignes bien définies : la littérature et l'enseignement. Dans la première, elle se consacra au roman populaire en publiant plusieurs collections et aussi des livres pour la jeunesse; elle fit connaitre les grandes œuvres classiques en créant des collections comme la Biblioteca Selecta ou la Biblioteca Sopena. Dans la deuxième, elle publia des dictionnaires, des encyclopédies et des manuels.

21 Saturnino Calleja acheta la librairie et l'imprimerie, fondées par son père, en 1879. Peu après, elles devinrent la Editorial Calleja, la maison d'édition la plus populaire en Espagne et en Amérique Latine à la fin du XIXe siècle. Il publia des milliers de livres. 
Son succès se doit aux petits prix de ses livres dont il publie de grandes quantités et aux illustrations qui les accompagnent et qui facilitent la lecture aux enfants. Il se spécialisa dans la publication de contes et obtint la faveur des plus jeunes qui connurent grâce à lui les grands auteurs des contes comme Andersen ou les frères Grimm. A part cela, il publia beaucoup de romans, parmi lesquels on trouve plusieurs romans populaires.

Le Fils du diable a été réédité en 2004 par Santillana et c'est précisément une édition réalisée à partir de celle de Saturnino Calleja au XXe siècle dans laquelle les illustrations jouent un rôle déterminant.

\section{Frère Tranquille (La Duchesse de Nemours)}

23 Ce roman se trouve dans le volume Les nuits de Paris. Il reçut d'abord le titre de $L a$ Duchesse de Nemours qui devint plus tard Frère Tranquille. Ce n'est pas un roman très connu de Féval. Malgré cela il fit l'objet de plusieurs traductions au XIXe siècle mais pendant le XXe elles diminuent notablement.

Il faut remarquer la traduction de Joaquina García Balmaseda (1837-1911), publiée en 1882. Elle avait déjà traduit Le Bossu en 1861 et Les Habits Noirs en 1864. Il s'agit d'une femme extraordinaire, actrice, journaliste, poète et écrivaine. Elle collabora à de nombreux journaux et revues, notamment à La Correspondencia de España; pour le feuilleton de cette revue elle traduisit plusieurs romans du français. Outre Féval, elle traduisit Émile Gaboriau, Richebourg, George Sand, Xavier de Montepin, Ponson du Terrail, Alexandre Dumas, Fortuné de Boisgobey et Georges Ohnet parmi d'autres.

\section{Le Bossu}

C'est sans doute le roman le plus connu de Féval et le plus traduit en Espagne, non seulement pendant le XIXe siècle mais aussi pendant le XXe siècle et même de nos jours. La dernière édition de ce roman date de 2010.

Comme nous l'avons signalé ailleurs ${ }^{13}$, dans son cheminement à travers l'imaginaire espagnol, le texte de Féval va être servi par les maisons d'édition, par les traducteurs, les adaptateurs et les illustrateurs.

Calleja et Bruguera, pour les maisons d'édition ; Jaume Juuez Castellà, Emilio Freixas ou Luis Palao, pour les dessinateurs ; José Antonio Vidal Sales, pour les adaptateurs ; Carlos Chíes, Javier de Zengotita, José Muñoz pour les traducteurs : ils ont tous contribué à répandre l'image d'Henri de Lagardère en Espagne.

Parmi les traducteurs du Bossu, nous aimerions nous attarder un moment sur José Muñoz Maldonado (1807-1875), connu aussi comme le vicomte de San Javier. Il s'agit d'un journaliste, romancier, historien, juriste et politicien espagnol. Il a dirigé de nombreuses revues dont le Semanario Pintoresco Español et El Museo de las Familias. Il aimait écrire des romans feuilletons et il a été un traducteur régulier des feuilletons français, comme ceux de Paul de Kock. Il a aussi traduit Les Misérables de Victor Hugo. En ce qui concerne sa traduction du Bossu, il prend beaucoup de libertés avec le texte. Le plus souvent, il le résume mais parfois il le réécrit en ajoutant des mots et des idées qui lui sont propres.

Il faut aussi mentionner que de nombreuses traductions du texte de Féval sont arrangées et préparées pour la jeunesse, surtout celles publiées par la maison d'édition 
Bruguera. Elles se présentent accompagnées d'une bande dessinée qui résume l'histoire et qu'on peut lire séparément de la version écrite. C'est un phénomène qui n'est pas exclusif à l'Espagne, en France aussi on peut trouver des adaptations similaires. Cela a certainement contribué à faire connaître le héros de Féval et son histoire.

Signalons encore que le roman se présente aux lecteurs espagnols sous des titres différents qui mettent en valeur les principaux personnages ou l'action la plus importante de Lagardère, son serment à Nevers.

\section{Les Habits Noirs}

31 Les traductions de ce roman se bornent au XIX siècle, il n'est pas repris pendant le XXe siècle. La raison s'en trouve peut-être dans la longueur et la variété des épisodes et des personnages.

\section{Le Capitaine Fantôme}

Dans ce roman, Féval met en scène la guerre de l'Indépendance, mais son jugement n'est pas objectif. Il ne présente pas la situation d'une manière équilibrée. $\mathrm{Ni}$ l'Angleterre ni surtout l'Espagne ne sont traitées avec équanimité. Sa condition de Français engagé dans son pays et se refusant à voir ses erreurs, l'aveugle et fait qu'il fausse la véritable portée du conflit. À cause de cela, malgré le succès de Féval en Espagne, ce roman n'a pas été traduit jusqu'en 2009, et encore s'agit-il d'une version tronquée. Il s'agit de la troisième partie du roman, intitulée "Talavera-de-la-Reina ", même si le titre demeure Le Capitaine Fantôme. C'est une édition réalisée à Talavera de la Reina pour commémorer le bicentenaire de la guerre de l'Indépendance. C'est peut-être parce que l'image de l'Espagne qu'il véhicule est trop lourde à porter pour le peuple récepteur. César de Chabaneil, le protagoniste, pense que l'Espagne se trompe d'ennemi et n'arrive pas à saisir, en étant le porte-parole de son auteur que la liberté prime sur le progrès et qu'aucun peuple ne peut accepter de perdre son identité.

\section{La Ville Vampire}

Comme pour le cas précédent, on ne trouve pas de traductions de ce roman au XIXe siècle. C'est dans la deuxième moitié du XXe siècle que la première traduction paraît. Cet intérêt est lié sans doute à la thématique du vampire, très travaillée par les maisons d'édition qui vont s'occuper de la traduction.

La maison d'édition Taber qui possédait une collection intitulée "Le roman fantastique " est fermée dès 1970, peu après la publication de la traduction de Féval, qu'on peut encore trouver chez les bouquinistes.

Jesús Palacios Trigo (1964) qui s'occupe de la préface à l'édition de Valdemar est un écrivain et critique de cinéma, particulièrement intéressé par le genre fantastique, coordinateur de plusieurs ouvrages qui traitent cette thématique. Valdemar publie des livres dans cette ligne-là. 


\section{George Sand} touristiques de l'Espagne. On se heurte ainsi au paradoxe que celle qui a critiqué les Majorquins a contribué et contribue toujours à faire leur renommée. L'édition publiée par Moll en 1993 ne blâme plus Sand pour ses commentaires négatifs sur les habitants des Baléares et souligne qu'elle est seulement un maillon de plus dans la chaîne des auteurs - parmi lesquels des Catalans comme Turmeda ou Eiximenis - ayant critiqué les 
mœurs de l'endroit. Le traducteur et auteur du prologue, Jaume Vidal Alcover, contribue à la renommée de Sand, à son autorité comme écrivain, à ce qu'elle devienne «la representant de tota quanta maldiença s'ha abocat sobre Mallorca $»^{20}$. Même la quatrième de couverture insiste sur cet aspect en remarquant la différence entre les reproches adressés par Sand à ses "hôtes" majorquins, souvent ancrés sur des préjudices, et son admiration presque béate pour le paysage de l'île. L'éditeur reconnaît aussi la valeur ajoutée de ces illustres visiteurs qui contribuent doublement au développement touristique : en créant une opinion de la part de la romancière, alors que le musicien déclenche la ferveur du pèlerinage à Valldemossa non seulement des amateurs de musique - à cause du Festival Chopin - mais de tous ces visiteurs curieux de connaître la demeure où le couple d'amants a passé la plupart de son séjour. À ce propos, le paratexte qui accompagne ces éditions du XXe siècle renforce ces deux critères puisque souvent il reproduit des images d'un élément typique de l'île, à savoir, l'olivier (Proa, Edicions 62), ou des paysages majorquins portés notamment sur la Chartreuse de Valldemossa (Clumba, Moll). Il ne manque pas non plus la référence au célèbre piano qu'Edhasa prend comme motif central. La personnalité de l'auteure reste aussi l'un des topiques qui apparait combiné avec les motifs antérieurs pour insister dans la controverse : l'édition de José J. de Olañeta choisit de combiner les falaises et les montagnes de la vallée du village de Valldemossa avec deux caricatures de Sand (le miroir drôlatique et George Sand et ses amis d'Auguste Charpentier, une aquarelle sur éventail, ce dernier élément étant bien propre à d'autres portraits célèbres de l'écrivaine).

41 D'une manière ou d'une autre les éditeurs modernes qui ajoutent des notices au texte de l'auteure portent sur cette antinomie des propos sandiens : Antoni Marí, en 1992 dans son prologue pour l'édition de Proa, estime cette œuvre «bizarre ». Il justifie ce qualificatif par plusieurs raisons : le moment de rédaction, les sources employées, la soi-disant volonté d'objectivité de Sand et la perspective qu'elle prend... Robert Graves, dont plusieurs éditions aussi bien en catalan qu'en castillan se réclament pour encadrer le livre, en fait la question essentielle de son intérêt :

Así fue como llegué al problema que me ha intrigado durante tanto tiempo : ¿qué fue lo que impulsó a George Sand a escribir de una manera tan desconsiderada y cruel sobre los mallorquines ?21

Le rapport avec Majorque reste essentiel pour d'autres publications récentes : ainsi le prouve le fait qu'à l'occasion du bicentenaire de sa naissance Sand ait été nommée fille adoptive de l'île par le Consell de Mallorca. Les arguments apportés comme qualités en disent long sur la considération qu'elle mérite de nos jours et reviennent sur les deux axes antérieurs : «en reconeixement als seus mèrits com a escriptora i intellectual, al mateix temps que insigne pionera de la promoció de Mallorca a nivell europeu $»^{22}$. Ce lien serait à l'origine de la publication en 2009 d'une nouvelle version de Histoire de ma vie en catalan dans un volume imposant qui, sans atteindre l'intégralité de l'autobiographie de Sand, en reprend les passages fondamentaux. Le choix fait partie des attentes du lecteur non-spécialiste actuel qui a sans doute entendu se répéter tous les clichés de la vie privée de Sand, ce que le livre se propose de corriger. Or, ce volume ne devrait qu'entamer une future collection devant incorporer "les obres de l'escriptora més lligades amb el seu sojorn a Mallorca l'hivern de 1838-39 $»^{23}$. À notre connaissance, cette série n'a pas eu de suite, étant à coup sûr le fruit de l'air du temps qui a réduit les budgets consacrés à la culture, notamment dans les universités puisque ce projet faisait partie d'une édition universitaire. Malgré tout, la tentative mérite 
d'être relevée vu la nature des liens évoqués: le voyage à Majorque reste un aspect mineur. À en croire les éditeurs, ce sont les aspects de "la culture et la modernité $»^{24}$ que Sand partage avec les Majorquins. L'écrivaine contribue donc à façonner une image, elle continue à travers les siècles à orienter l'opinion.

En dehors des précédentes, les publications espagnoles portent leur choix sur le thème clé dans l'écriture sandienne : l'amour. Toutefois si ce sentiment mérite chez l'auteure des nuances multiples allant depuis la philosophie jusqu'à la politique ou la sociologie, ces deuxièmes lectures ne sont pas visées. Les éditions, surtout en ce qui concerne le XIXe et première moitié du XXe siècle, traduisent des histoires d'amour commodes, sans atteintes à la morale de l'époque. Ainsi les Dames vertes: suite à l'invitation des éditeurs qui lui demandaient un ouvrage dans le genre de celui de La Mare au diable, Sand avait donné ce récit en 1857 pour débuter dans Le Monde illustré sous le format du feuilleton. Elle interprète la sollicitation comme une exigence fâcheuse ${ }^{25}$ et se résout à faire passer les questions religieuses et politiques au deuxième rang et à mettre l'accent sur l'action. La décision adoptée en tant qu'auteure est dans l'air du temps : les adeptes du folletín prisent l'intrigue sentimentale avant tout comme en témoigne Galdós en 1884, qui, d'un regard critique, estime «El editor es hombre que conoce el paño, y nos dice : Quiero una obra de mucho sentimiento, que haga llorar a la gente y que esté bien cargada de moralidad $»^{26}$. Sur ce volet figurerait de la part de Sand Jean de la Roche (1859) car la thématique de la réussite de l'amour conjugal dans le bonheur, le sacrifice de la jeune Miss Love en faveur de son frère, le fait qu'il ne soit pas question d'une passion ardente ou d'adultère sanglant constituaient des composantes qui convenaient parfaitement à une société traditionnelle comme la société espagnole.

Tamaris (1862) s'ajoute à la liste des plus édités en tant qu'histoire d'amour entre un jeune homme et une veuve, tout comme Mauprat où le protagoniste ne suscite le bonheur de sa bien-aimée qu'après un long chemin d'épuration.

Dans ce sens le Marquis de Villemer, popularisé par les abondantes adaptations au théâtre, reproduit ce thème de l'institutrice maltraitée par la patronne, ce qui permet une description de la vie aristocrate. Car les malheureux voués à des renoncements sont dans les habitudes du public espagnol vu le succès des mélodrames ${ }^{27}$ : la bonté de Madeleine soignant le Champi n'émeut-elle pas encore de nos jours? Ce n'était pas en vain que le roi Carlos IV était venu en aide à des enfants abandonnés et que pendant les années suivant la guerre d'Indépendance espagnole on avait pris conscience du problème national que ce fait entraînait ${ }^{28}$. La littérature pouvait bien en parler, comme le témoigne Francisco el Expósito.

En dernière instance les éditeurs espagnols puisent aussi dans le réservoir des contes : La reina Coax y otros relatos, Cora, la Copa vont de pair avec celui que Sand a écrit en 1850, l'Histoire du véritable Gribouille, pour la fille d'Alphonse Fleury. Ce dernier a vu le jour récemment sous l'adaptation de Maria Luise Völter aussi bien en castillan qu'en catalan ${ }^{29}$. Sand est dans ce cas versée d'une manière indirecte, en passant par l'allemand de son adaptatrice, vu que les traducteurs sont des spécialistes de cette langue. Ces volumes méritent d'être cités, non seulement par la beauté des illustrations, mais aussi par leur prologue. À l'évidence, le fait de viser un public d'enfants pousse l'auteur de l'introduction à déceler l'identité féminine cachée sous le pseudonyme. Suit alors une synthèse biographique où il est facile de repérer l'idéologie conservatrice qui la sous-tend et qui fait de George Sand une âme vaillante mais dans les limites de la morale bienséante, à en juger par les arguments sur son mariage : 
«Però el matrimoni amb el senyor baró no va ser feliç. Aurore va perdre el seu marit i se'n va anar a París a mb els seus fills $»^{30}$ de même que l'euphémisme à propos de la liaison avec Chopin : «Va viure molts anys amb el compositor Frederic Chopin »"

Étant donné que la valorisation d'un auteur lui parvient aussi par les éléments du paratexte, il faut relever un deuxième type d'information: les noms qui ont prêté leur plume à la version et à la présentation des ouvrages de Sand. L'éventail est large en possibilités : s'il faisait partie des mœurs du temps que les éditions du XIXe siècle ne citent même pas le traducteur ou le cachent derrière des sigles, pour Sand ce phénomène n'est pas fréquent. Pendant la période envisagée, elle compte avec des traducteurs renommés tels que Eugenio de Ochoa $^{32}$, fameux aussi par ses propres ouvrages de fiction ainsi que par ses responsabilités comme directeur de El Artista, une revue littéraire dont l'existence fut courte mais importante. De sa vie nous ne relèverons que les séjours passés à Paris à la fin des années 30 : Ochoa a donc pu être témoin de l'élan romantique, ce qui très probablement a imprimé sa marque et sur son écriture et sur ses idées littéraires. Cet esprit novateur fait partie des fondateurs de $E l$ Artista qui prend comme modèle la publication française portant ce même nom (L'Artiste) de Achille Ricourt avec qui George Sand ${ }^{33}$ collaborait aussi. Ochoa et ses adjoints - d'après Genoveva Elvira López ${ }^{34}$-, mécontents du niveau culturel de leurs compatriotes, cherchaient à créer un moyen de diffusion pour ces nouvelles idées. Le romantisme leur apparaissait novateur ${ }^{35}$. La collaboration avec I. Sancha, l'imprimeur de El Artista, accentue l'activité d'Ochoa comme traducteur. Pour ce qui est du style de George Sand, il en avait l'expérience, car entre 1836 et 1851 il avait versé au castillan presque une œuvre par année. Son biographe estime qu'Ochoa s'en tenait aux textes où dominent «la pasión femenina y la inspiración sentimental ${ }^{36}$ au détriment de ceux qui prêchent des revendications politiques. A notre avis, Ochoa était dans l'air du temps. Or, d'un autre côté le biographe demeure influencé par les stéréotypes, puisqu'Indiana, par exemple, contient une remise en cause des principes sociaux de l'époque. Les versions publiées dans la période qui nous occupe ne sont pourtant que des rééditions : Ochoa avait traduit Leoni Leone en 1837 pour une collection intitulée "Mañanas de primavera », dont ce titre constituait le premier volume, le troisième étant Indiana. De même El Secretario íntimo était paru cette année chez Sancha occupant deux volumes de la Colección de novelas de los más célebres autores extranjeros ${ }^{37}$. En $1888 \mathrm{ce}$ n'est plus Sancha qui la reprend mais Daniel Cortezo en charge de l'entreprise Arte y Letras, confrontée à des difficultés financières. Cortezo doit amorcer une réduction de coûts qui sacrifie, entre autres ${ }^{38}$, des actions de marketing. L'année 1888 la Biblioteca Artes y Letras ne publie que deux volumes, l'un correspondant à Sand, l'autre à Sandeau, les avant-derniers d'une série qui avait convoqué des noms tels que Andersen, Shakespeare, Clarín, Daudet, Pereda, Dickens, Poe, Hoffmann... et dont la disparition se produit en 1891.

El Secretario íntimo a aussi été versée au castillan par le Vizconde de San Javier, titre de noblesse de José Muñoz Maldonado qui effectue plusieurs changements sur le texte originel ${ }^{39}$.

Plus récemment Sand a attiré l'attention de Fernando García Burillo, l'un des fondateurs des Ediciones del oriente y del Mediterráneo née en 1989 dans le but de faire connaître des auteurs marocains, libanais, algériens, turcs, iraniens... inconnus du lecteur espagnol. Il participe à ce projet éditorial en qualité de traducteur assidu depuis 
le turc et le français, langue de laquelle il a traduit André Gide, Mohamed Dib ou Lise London.

Des écrivains réputés se sont aussi occupés des versions sandiennes: que dire de l'argentin Jorge Luis Borges? ou encore de Joaquina García Balmaseda, (1837-1911) une écrivaine dont la tâche touche à plusieurs genres : depuis les manuels scolaires jusqu'à la poésie? Son activité de création allait de pair avec sa collaboration comme traductrice dans La Correspondencia de España. Sur ce périodique, en plus des trois ouvrages de Sand, elle avait traduit Dumas, Féval, Ponson du Terrail, Montepin, Souvestre, Ohnet, ce qui la profilait comme bonne connaisseuse du roman populaire. De surcroît, elle devait se sentir proche de Sand car son parcours permet d'entrevoir des positions communes pour ce qui est de la lutte en faveur des conditions des femmes qui la mettaient aux prises avec la société traditionaliste d'Isabel II ${ }^{40}$.

Moins connue parce qu'éclipsée par sa sœur et les circonstances historiques de l'époque est la romancière Magda Donato, pseudonyme de Carmen Eva Nelken (1906-1966), journaliste spécialisée dans l'évolution de la classe bourgeoise dont la tâche dans des journaux madrilènes comme El Imparcial, Estampa ou El Liberal consistait essentiellement à informer le public espagnol sur les progrès des femmes dans les droits sociaux. En tant qu'actrice de théâtre, elle participe à des projets rénovateurs de cet art et elle-même y contribue en écrivant des scénarios de pièces destinées aux enfants tout en essayant de montrer le nouveau modèle de socialisation en marche pendant la IIe République. Sa familiarité avec ce public lui vient aussi de sa liaison depuis 1914 avec l'illustrateur et écrivain Salvador Bartolozzi, l'un des dessinateurs attitrés de la maison éditoriale Calleja, fort célèbre, et dont les principes suivaient de près ceux de Hetzel en France. Ses travaux dans ce domaine héritent des influences de la Institución Libre de Enseñanza et du Krausisme, dont le but consiste à réformer la société espagnole en bannissant la religiosité traditionnelle au profit d'une morale austère, de la promotion scientifique et d'une religion à demi sécularisée.

Quant au journaliste et écrivain Carlos de Arce (1958-2007), il a souvent consacré ses articles dans la presse à des sujets littéraires alors que comme créateur il a surtout cultivé le roman et le théâtre. À la fois il a été traducteur et éditeur, il a fondé la maison d'édition Seuba où Sand figure sur le catalogue.

L'auteur majorquin Juan Bautista Enseñat (1854-1922), journaliste et historien, a débuté dans la carrière littéraire en écrivant en français, puisqu'en 1878 il s'était installé pour quelques années à Paris. Il a toutefois joué un rôle parmi l'intelligentsia espagnole de l'époque vu sa prolixe activité culturelle : fondateur de $E l$ Ideal, il a été le rédacteur en chef d'El Globo, organe des partisans de la République. De surcroit, il a collaboré avec plusieurs journaux madrilènes, barcelonais et parisiens et il a représenté l'Espagne lors de plusieurs expositions à l'étranger. En tant qu'auteur, il a publié plus de soixante-dix titres parmi lesquels La pasión carnal ou La emperatriz Eugenia, íntima, María Antonieta (su vida íntima). Se partageant entre l'écriture et la traduction, il a versé à l'espagnol deux textes sandiens de même qu'il a traduit Lourdes de Zola.

Plus récemment Sand a été traduite par Xavier Costa Clavell (1923-2006), journaliste et écrivain galicien, auteur de quelques romans mais surtout d'essais.

Du fait qu'Un hiver à Majorque bénéficie du plus grand nombre d'éditions, il concentre un foisonnement de procédures d'édition. Phénomène rare, une édition pourtant moderne (Cort, 1999) ne cite pas le traducteur, ce qui indique à quel point le livre est devenu un objet touristique à valeur commerciale au détriment de sa qualité littéraire. 
$\mathrm{Au}$ contraire, d'autres prennent des traducteurs professionnels mais en général, ces versions sont attribuées à des personnages réputés : ainsi l'écrivain Valentí Puig dont l'œuvre en catalan et en espagnol a été primée plusieurs fois ; le journaliste et politicien Josep Moll Marquès, Enrique Azcoaga poète et romancier reconnu, appartenant à la génération de 36 ; Luis Ripoll, propriétaire d'une maison d'édition à Majorque et auteur de Chopin: su invierno en Mallorca, ou Carmen Gallardo, la veuve du poète Enrique de Mesa décédé pendant la guerre d’Espagne et qui était connue par ses idées communistes.

Les versions sandiennes ont aussi mérité d'être traitées par des traducteurs professionnels reconnus, ce qui à nos yeux, indique la valorisation de l'auteure : Amaya García Gallego qui parmi d'autres a traduit Malraux et Zola et dont une importante partie de la tâche se consacre à la littérature pour enfants (d'où sa contribution sandienne); Elena del Amo, écrivaine qui exerce aussi comme scénariste de courts métrages et traductrice, activités où elle a obtenu plusieurs prix.

Elisabeth Falomir Archambault chargée, entre autres, de la traduction de Flaubert ou de Stendhal, ainsi que d'un recueil de contes appartenant à plusieurs maitres des lettres françaises (Stendhal, Hugo, Flaubert, Mérimée, Verne, Zola).

Juan José Delgado Gelabert, chargé de traductions en rapport avec l'Italie et sa culture notamment sur Venise -, ce qui explique sa version de En Venecia. Sans oublier que le regain d'intérêt des milieux académiques pour l'écrivaine a produit certains fruits comme c'est le cas de David Marín Hernández, professeur de l'Université de Málaga qui s'est récemment occupé de Diario de una viajera durante la guerra.

Ces mêmes pratiques se reproduisent pour les publications en langue catalane: Just Cabot (1898-1961) figure parmi les journalistes catalans prestigieux du début du XXe siècle. Il a été le directeur de la revue culturelle Mirador. Sans doute, comme écrivain en exil à Paris, il était attentif à la culture française puisqu'il a mené des études sur Balzac et Stendhal.

Jaume Vidal Alcover (1923-1991), Antoni Lluc Ferrer (1949), tous les deux écrivains majorquins ayant traduit respectivement Proust, le premier et Voltaire et Bernanos, le dernier, consacrent leurs efforts à Un hivern a Mallorca. Cet ouvrage compte de même avec la traductrice professionnelle et vouée aussi au monde éditorial, Marta Bes Oliva dont la version est reproduite par de prestigieuses maisons d'édition, telles qu'Edhasa ou Proa.

61 Les universitaires ont aussi contribué à la diffusion de Sand: Caterina Calafat, de l'Université des îles Baléares a travaillé avec Brigitte Diaz (Université de Caen) pour les notes sur l'ouvrage de Sand. À l'Université de Lleida Cristina Solé a traduit La petite fadette.

Or, comme le remarquait G. Genette dans Seuils ${ }^{41}$, le texte ne parvient pas à nu aux yeux du lecteur. Parmi les éléments essentiels du paratexte dans les traductions, il faut relever les prologues. Soit qu'ils présentent l'auteur et le livre, qu'ils contribuent à élucider les passages les plus complexes, soit qu'ils incorporent des remarques sur le procès de la traduction, ils produisent un "horizon d'attente" que les éditons sandiennes ne manquent pas d'exploiter. C'est le cas de la version de Cátedra, maison d'édition réputée pour son pari d'éditer les classiques selon des principes philologiques stricts, qui avec Matilde Santos accompagne La charca del diablo d'une large biographie 
de Sand, de repères en politique et littéraire sur son époque pour se concentrer sur l'analyse de l'œuvre.

Il n'est pas vain que lorsque l'auteur de la présentation diffère du traducteur, ce soit pour ajouter un certain prestige à l'édition : particulièrement pour Un hiver à Majorque dont plusieurs éditions s'autorisent d'autres voix. C'est le cas de Gabriel Alomar, auteur d'origine majorquine très influencé par le modernisme, ce mouvement de forte emprise en Catalogne, écho de l'art nouveau, dont la volonté de moderniser la société catalane née de la Restauration pouvait être un atout en 1902 pour l'édition de Bartolomé Rotger.

Les versions de Olañeta et de Proa - donc en castillan et en catalan - font appel à Robert Graves, auteur lui-même d'un essai sur cet ouvrage qui a accompagné la version en anglais dont il s'est chargé lui-même. À notre avis, Graves apporte une double valeur : sans aucun doute sa condition d'écrivain reconnu, à laquelle s'ajoute sa condition d'étranger venu habiter l'île de Majorque et pouvant donc analyser avec un regard plus objectif le choc culturel auquel s'est confrontée Sand. En fait, ses arguments à ce propos dépassent l'analyse du problème moral auquel l'auteure a été confrontée, mais son originalité est celle d'envisager de surcroît la barrière linguistique entre les visiteurs français et leurs hôtes. Sans gracier George Sand, il attribue l'échec du séjour à plusieurs causes, comme la jalousie de Solange ou encore le remords d'un Chopin dédaigneux des classes populaires et par ailleurs en proie à sa foi catholique.

Dans le cas de l'édition en catalan, Proa a tenu à bien encadrer le texte sandien : à la voix de Graves présentée en épilogue se joint celle de l'essayiste et poète Antoni Marí: après avoir synthétisé la biographie des protagonistes, Marí remarque à quel point l'expérience sur l'île faisait partie d'une philosophie héritée de Rousseau. Loin de s'en tenir à une analyse morale, le critique prend une perspective littéraire et envisage le moment d'écriture, les sources et les points de vue du récit. Pour bien réussir le volume, le texte écrit s'accompagne des illustrations du livre de J.-B. Laurens, voyageur français qui a aussi visité l'île et dont elle a fait la connaissance à Paris deux ans après son périple.

66 Un esprit rigoureux guide aussi la démarche de Vidal Alcover qui commence par analyser les aspects saillants de la vie de George Sand. À ses yeux, son style de vie justifierait l'accueil hostile de l'étrangère au sein d'une société à mœurs traditionnelles. Il attribue à la condition petite bourgeoise de la romancière ses mésaventures lors du déplacement. Et s'il reconnaît des erreurs d'appréciation aussi bien chez Dupin que chez Graves, il les excuse en soulignant l'évolution que la société insulaire a réalisée depuis ces temps. Le prologue, pourtant, veut dépasser les topiques et se livre à une réflexion littéraire : il analyse les sources utilisées par Sand et surplombe l'évolution de ce texte par le biais de ses différentes éditions françaises sans oublier les traductions sur la Péninsule ibérique. Le volume, qu'encadrent les portraits de George Sand pour le début et de son fils - à la fin - réalisés par Delacroix, est de plus imagé à l'aide de Recuerdos i Bellezas de España (1842) de Francisco Javier Parcerisa, qui a consacré trente années à l'élaboration du volume ayant encore de nos jours une valeur comme entreprise de description du patrimoine et où les Baléares apparaissent comme un territoire méconnu des Espagnols, riche en exotisme et pittoresque par la virginité de la nature et sa population.

67 Parmi les préfaciers illustres on ne peut pas oublier Carme Riera, écrivaine de premier rang, devenue membre de l'Académie espagnole de la langue en 2012. Si sa présentation 
à Un invierno en Mallorca fait pendant à la voix de l'écrivain traducteur, Azcoaga, nous croyons que là où elle brille dans toute sa splendeur c'est dans Història de la meva vida. Sous une épigraphe provocatrice «Les porcades ${ }^{42}$ de George Sand », Riera entreprend la biographie de son homologue française mais bientôt elle s'évertue à imaginer les obstacles qu'elle a dû vaincre pour réaliser ses vœux en littérature. De ce point de vue, le travestissement n'apparaît que comme un moyen pour affirmer cette volonté. Et c'est encore la fermeté de son caractère qui la livre à toute une stratégie pour conquérir le cœur de Chopin. Riera refuse de livrer au lecteur l'image d'une passion édulcorée. En revanche, elle décortique leur séjour à Majorque pour conclure que la vie en commun avec un individu difficile - Chopin - ne pouvait pas être simple même dans ce paradis des Baléares. L'ironie de Riera s'en prend, en guise de conclusion, aux propos de Rubén Darío, poète ayant visité aussi Majorque, dans la critique qu'il porte contre Sand et son affection au porc. Les termes du poète rebondissent contre l'étendard de la romancière catalane :

Tal vegada allò que més li molesta, encara que no se n'adoni, és constatar que ella es va comportar com un marinerfenici: les porcs foren Sandeau, Vigny, Musset, Mallefille o el mateix Chopin ${ }^{43}$.

\section{Conclusion}

On peut encore trouver certains des livres de Féval en Espagne, néanmoins rien de comparable à ce qui était offert pendant le XIXe siècle et la première moitié du XXe siècle. En revanche, George Sand est devenue une auteure classique aux yeux du public espagnol comme du français. Malgré tout, un halo de curiosité malsaine continue à teinter l'identité de la romancière au point que même un journal contemporain, Diario Público a pu l'héberger sous la rubrique de «Literatura prohibida» en rappelant la censure que l'Église a autrefois fait peser sur cette personne et en la louant, en revanche, à cause de sa préoccupation sociale.

69 A l'exception de la littérature pour la jeunesse où aussi bien Féval que Sand continuent à être édités, le premier est réduit aux étagères des bibliothèques publiques si l'on excepte quelques produits symboliques ou fantastiques. Pour ce qui est des éditions de Sand, elles témoignent de la richesse des interprétations qui ont été proposées, étant donné que son succès relève de deux causes : la valeur (qui a pu se confondre avec une logique d'édification) $)^{44}$, et un intérêt pittoresque, lié à son déplacement à Majorque et au témoignage qui en est issu. À ce propos son livre fait presque figure d'un souvenir original qui résiste à la standardisation d'un monde globalisé.

Mais dans les deux cas le succès n'est pas comparable à celui obtenu dans le passé. À l'exception de quelques titres significatifs, les œuvres de ces deux auteurs sombrent dans l'oubli et se trouvent confondues avec la production de leur époque, qui souffre, la plupart du temps, d'un pareil destin. 


\section{Annexes}

\section{Traductions de Paul Féval}

\section{1.-Traductions de Paul Féval au XIXe siècle (à partir de 1850)}

\section{Les Mystères de Londres, 1843-1844}

-Los Misterios de Londres, imprimerie de Ignacio Cumplido, México, 1856.

-Los Misterios de Londres, D. Juan de Mariana y Sana, Valencia, 1867.

Le fils du diable, 1846

-El hijo del diablo, traduit par L.G. et P.N.O., imprimerie de M. Aguilar, Málaga, 1850.

-El hijo del diablo, traduction de J. M. C.G., Est. Tip. de Mm. Martinez y Bogo, Madrid, 1861.

-El hijo del diablo, imprimerie La Elegancia de A. Alienza, Irún, 1863.

-El hijo del diablo, traduction de Víctor Balaguer et Francisco José Orellana, láminas de E. Planas, Biblioteca de Ambos Mundos, Barcelona 1871.

-El hijo del diablo, in Heraldo de Madrid, 1/03-10/05, 1892.

-El hijo del diablo, Impr. y Estereotipia de El Liberal, Madrid, 1893.

Les Nuits de Paris (Frère Tranquille =La duchesse de Nemours), 1851-1853

-Fray Tranquilo, traduit pour le feuilleton de Las Novedades, imprimerie J. Trujillo, Madrid, 1860.

-El hermano pacífico, traduit par M. de la R., imprimerie Peninsular, Barcelona, 1878.

-La Duquesa de Nemours, version de Joaquina García Balmaseda, La Correspondencia de España, Madrid, 1882.

-La Duquesa de Nemours, imprimerie de Ambrosio Rubio, Málaga, 1886.

Le Bossu, 1857

-El Jorobado, traduit par Doña Joaquina García Balmaseda, imprimerie de La Correspondencia de España, Madrid, 1861.

-El Jorobado, traduit par Manuel C. Irtuate, imprimerie de V.C.Torres, México, 1862.

-Aurora de Nevers, traduction José Coroleu, Librería Española, Barcelona, 1864.

-El Jorobado, imprimerie et librairie de Ambrosio Rubio, Málaga, 1879.

-Enrique de Lagardère, imprimerie de Henrich et Cie, Barcelona, 1892.

-El Jorobado, Málaga, 1898.

-El Juramento de Lagardère, Saturnino Calleja, Madrid, 1898.

Les Habits Noirs, 1863

-Los Hábitos negros, traduction de Joaquina García Balmaseda, imprimerie de La Correspondencia de España, Madrid, 1864.

-Los Hábitos negros, traduction de Joaquina García Balmaseda, Imprimerie et litographie de El porvenir, Sevilla, 1866.

-Los Hábitos negros, El Popular, Granada, 1891. 


\section{2.-Traductions de Paul Féval au XXe et XXle siècles} Fernández, Madrid, 1906 (réédition 1908).

117 -El Jorobado o Enrique de Lagardère, Traduction de Carlos Chíes, Maucci Frères et Fils, Buenos Aires, México, Imprimé par Sopena, Barcelona, 1907 (rééditions 1920, 1928, 1931).

Les Mystères de Londres, 1843-1844

-Los Misterios de Londres, traduction de Johanna Givanel, collection roman gothique et feuilletonesque, Tabler, Barcelona, 1970.

-Los Misterios de Londres, traduction, introduction et notes de Gregorio Cantera, Letra Celeste, Madrid, 2000.

Le fils du diable, 1846

-El hijo del diablo, Sopena, Barcelona, 1906 (réédition 1930).

-El Castillo maldito, Saturnino Calleja, Madrid, 1907.

-Los Vampiros, segunda parte de El Castillo maldito, Saturnino Calleja, Madrid, 1907.

-Los mercaderes de plata, tercera parte de El Castillo maldito, Saturnino Calleja, Madrid, 1907.

-La Casa de Geldberg, cuarta parte de El Castillo maldito, Saturnino Calleja, Madrid, 1907 .

-Los tres hombres rojos, quinta parte de El Castillo maldito, Saturnino Calleja, Madrid, 1907,

-El Misterio de la Trinidad, sexta parte de El Castillo maldito, Saturnino Calleja, Madrid, 1907.

-Los bastardos de Bluthaupt, séptima parte de El Castillo maldito, Saturnino Calleja, Madrid, 1907

-El Barón de Rodach, octava parte de El Castillo maldito, Saturnino Calleja, Madrid, 1907.

Reproduction de l'édition de Saturnino Calleja, Madrid, 1907, Edaf, Santillana, Madrid, 2004.

\section{Les Nuits de Paris (Frère Tranquille =La duchesse de Nemours), 1851-1853}

-El hermano pacífico, Apostolado de la Prensa, Madrid, 1910 (réédition 1954).

-El hermano pacifico, Lecturas para todos, Madrid, 1934.

Le Bossu, 1857

-El juramento de Lagardère (Le serment de Lagardère), arrangée par J. Muñoz, Edition révisée et illustrée avec des gravures originales de Luis Palao, Saturnino Calleja -Aurora de Nevers, arrangée par José Muñoz, Saturnino Calleja, Madrid, 1906 (1908).

-Cocardasse y Passepoil (Troisième partie de El juramento de Lagardère), Saturnino Calleja, Madrid, 1912.

-El Jorobado o Enrique de Lagardère, traduit par Carlos Valverde López, imprimerie La Unión Mercantil, Málaga, 1912.

-jLagardère! (Le Bossu), adaptation moderne, éd. et imprimerie Garrofé, Barcelona, 1925.

-El Jorobado o Enrique de Lagardère, Prensa Nueva, Madrid, 1925.

-El Jorobado, Lecturas para todos, Madrid, 1935. 
-Aurora de Nevers, traduction de Manuel P. Cáceres, Madrid, 1946.

-El Juramento de Lagardère, version refondue par Javier Zengotita, collection Oasis, $\mathrm{n}^{\mathrm{o}}$ 106, Couverture originale d'EmilioFreixas, Bruguera, Barcelona, 1947.

-El Juramento de Lagardère, version refondue par Javier Zengotita, couverture originale d'Emilio Freixas, Edi. Reguera, Barcelona, 1947.

-La Venganza de Lagardère, d'après le roman de Paul Féval Le Chevalier de Lagardère, Edit. Alas, Barcelona, 1947.

-El jorobado, traduction du français de Angel Herrera Bienes, Notice préliminaire de F.S.R., Collection Crisol, (Creuset), Aguilar, Madrid, 1952, (rééditions 1960, 1964).

-El Jorobado, Traduction de J.G.B., Editions Apostolado de la Prensa, Madrid, 1954.

-Enrique de Lagardère, Traducteur : José Antonio Vidal Sales, partie graphique de Jaime Juez Castella, Collection Histoires, Bruguera, Barcelona, 1958 (réédition 1963).

-El Jorobado o Enrique de Lagardère, Editions Lorenzana, Barcelona, 1964.

-El caballero de Lagardère (El jorobado), Traduction A.J. Durán Rousseaux. Illustrations : Juan Pale, Cromoherma, Sriven M.G., Editions Delos Aymà, S.L., Barcelona, 1964.

-El Caballero de Lagardère (El jorobado), Traduction A. J. Durán Rousseaux, Círculo de Lectores, Barcelona, 1968.

-El Jorobado o Enrique de Lagardère, Larraiza, Pamplona, 1970.

-El Jorobado. Las aventuras de Lagardère, Los amigos de la Histoira, Madrid, 1970.

-El Juramento de Lagardère, version de Javier Zengotita, Rodegar, Barcelona, 1970.

-Enrique de Lagardère, adaptation de J.A. Vidal Sales, collection Joyas Literarias Juveniles (Bijoux littéraires pour la jeunesse), Illustrée, Bruguera, Barcelona, 1971, (réédition 1975).

-El Jorobado o Enrique de Lagardère, Edit.Vasco Americana, Bilbao, 1971.

-El Caballero de Lagardère, Fher, Bilbao, 1972 (réédition 1974) .

-El Juramento de Lagardère. El Jorobado, Petronio, Barcelona, 1973.

-Enrique de Lagardère, adaptation de Maricel Lagresa Colom, illustrations: Antonio Carrillo, Bruguera, Barcelona, 1975.

-El Jorobado o Enrique de Lagardère, Ramón Sopena, Barcelona, 1978.

-El Juramento de Lagardère, Editors, D.L., Barcelona, 1987.

-El Jorobado o Enrique de Lagardère, Cultura y Progreso, Bilbao, 1980.

-El Jorobado o Enrique de Lagardère, PTD, D.L., Alcalà de Henares, 1993.

-El Jorobado o El Juramento de Lagardère, PPP, Madrid, 1990.

-El Juramento de Lagardère, Iberlibro, D. L., Barcelona, 1990.

-El Jorobado, Traduction et notes : Magalí Martínez Solimán. Épilogue : Luis Alberto de Cuenca. Illustrations : Janet Lange, J.A.V. Foulquier, F. Robincaut, De. Coppin et A.Belin, Anaya, Madrid, 1995.

49 -El Juramento de Lagardère, roman adaptée par José Muñoz, édition illustrée et révisée avec des gravures originales de Luis Palao, Edaf, Santillana, Madrid, 2004.

-El jorobado. I, El pequeño parisien, Rueda, Madrid, 2005. 


\section{Traductions de George Sand}

En langue castillane :

\section{Le Capitaine Fantôme, 1861}

La Ville Vampire, 1875

-La Ciudad Vampiro, Buenos Aires, 1972. 2002).

\section{3.-Traductions sans date au XXe siècle}

-El hermano tranquilo, R. Angles. Madrid.

Le fils du diable, 1846

Le Bossu, 1857

-Enrique de Lagardère, Ed. Ameller, Barcelona. Fernando García Burillo. Gelabert y Correa

Antonia : novela escrita. Madrid, s.n. 1885.

-Enrique de Lagardère, adaptation J.A. Vidal Sales, illustrations : Antonio Pérez Carrillo, (édition avec d'autres romans), Planeta De Agostini, D.L., Barcelona, 2009.

-El Jorobado, Signo, D.L., Pozuelo de Alarcón, Madrid, 2010.

Méndez (seulement présente la traduction de la partie intitulée Talavera de la Reina), Canseco Editores S.L. , Talavera de la Reina, 2009.

-La Ciudad Vampiro, in Nuevas historias de fantasmas, Taber, Barcelona, 1969.

-La Ciudad Vampiro, traduction Marta Pérez, Fontamara, Barcelona, 1982.

-La Ciudad Vampiro: una peripecia gótica de Ann Radcliffe, traduction : Jacobo Rodríguez, prologue : Jesús Palacios, Valdemar, Madrid, 1998 (réédition 2007).

-La Ciudad Vampiro, traduction: Jacobo Rodríguez, RBA Colecccionables, Barcelona,

Les Nuits de Paris (Frère Tranquille =La duchesse de Nemours), 1851-1853

-El hijo del diablo, traduction de Gregorio Urbano Dargallo, M. Guijarro, Madrid.

-El Jorobado (El caballero Enrique de Lagardère), El Cosmos Editorial, Madrid.

-El Jorobado o Enrique de Lagardère, trad. de Carlos, Chíes, Sopena, Barcelona.

-El Jorobado. Enrique de Lagardère, version espagnole de J. Sirvent, Ed. G. P., Barcelona.

-El Juramento de Lagardère, Aurora de Nevers, Gabriel L. del Horno, S.A., Madrid.

-El Juramento de Lagardère, adaptation de $\mathrm{M}^{\mathrm{a}}$ Dolores García Lomas, Mateu, Barcelona.

Los amantes de Venecia : correspondencia (1833-1840); seguida del Diario íntimo de George Sand, Madrid, Ediciones del oriente y del Mediterráneo, 2004. Traducteur, prologue, notes :

Andrés. Un ramillete de jazmines, Madrid, s.n., 1857. Traducteur, prologue, notes : Mariano

El caballero Mauprat, Madrid, J. Pérez del Hoyo, 1969.

El caballero Mauprat, Madrid, Revista Literaria, "Novelas y cuentos”, 1930. 
Los caballeros de Bois-Doré, Madrid, s. n., 1922. Traducteur: Magda Donato [pseud. De Carmen Eva Nelken]

Los caballeros de Bois Doré, París, 1869. Roman traduit pour El Correo de Ultramar.

Cartas de Musset y George Sand, Buenos Aires, Inter-Americana, 1945. Traducteur, prologue : Jorge Luis Borges.

El castillo de Flamarande, Madrid, El Cosmos Editorial, 1887. Traducteur : P. San Román.

Cesarina Dietrich, Madrid, El Cosmos, 1888. Traducteur : Joaquina García Balmaseda.

La copa. Cuento de hadas, Barcelona, Imprenta de la Renaixensa, 1876.

El corte de genio. Novela, Manila, Ramírez y Giraudier, 1877.

La charca del diablo, Barcelona, Bruguera, 1969. Traducteur : Carlos de Arce; Prologue : Angeles Cardona de Gisbert [réédition : 1972, 1973, 1974]

La charca del diablo, Barcelona, Seuba, 2001. Traducteur : Carlos de Arce.

La charca del diablo, Madrid, Cátedra, 1989. Traductrice : Matilde Santos. Prologue et notes : Matilde Santos.

La charca del diablo, Barcelona, Vilcar, 1950 ? Adaptation de Seza [pseudonyme - Genre littérature pour enfants]

La charca del diablo : novela folletisnesca, Madrid, Revista Literaria, 1934.

La charca del diablo : una novela folletinesca completa, Madrid, Dédalo, 1940-1944.

La charca del diablo, Barcelona, Planeta-Agostini, 1999. Version bilingue et simplifiée.

La ciudad negra, Barcelona, Casa editorial Maucci, 1900. Traducteur : Emilio Longan.

Cora, Madrid, Velecio Editores, 2008. Traducteur, prologue: Johanna Laure Pérez Strand.

Correspondencia Gustave Flaubert y George Sand, Barcelona, Marbot, 2010. Traducteur, notes et épilogue : Albert Julibert. Prologue : André Comte-Sponville

Cuentos de una abuela, Madrid, Trama, 1998. Traducteur: Amaya García Gallego [réédition : 2006]

El misterio de las damas verdes, Madrid, Debate, 1984.

El misterio de las damas verdes, Madrid, Dédalo, 1940-1944.

El misterio de las damas verdes, Barcelona, La Novela Breve, 1910.

Las damas verdes, Madrid, Prensa Nueva, 1925. Illustrateur : Revel.

Las damas verdes, Madrid, Imprenta de La Correspondencia de España, 1863.

Diario de una viajera durante la guerra, Málaga, Servicio de Publicaciones de la Universidad de Málaga, 2005. Traducteur, prologue et notes : David Marín Hernández.

Diario de una viajera durante la guerra, Madrid, Libros de la ballena, 2012. Traducteur: Elisabeht Falomir Archamabult, prologue: Laura Freixas. Appendices : Julián Díazet Laura Cagüe Fernández.

Los dos hermanos, Barcelona, Mundi libro, 1973. Traducteur : Costa Clavell, illustrateur : Mª Paz García-Borrón.

Los dos hermanos, Madrid, El Cosmos Editorial, 1897. Traducteur : C. Vidal.

Ella y él, Barcelona, Debate, 2003. Traducteur : Luis Cánovas.

Ella y él, Barcelona, Hmsa, 1985. Traducteur : ? Illustrateur : Rubén Morales 
En Venecia, Palma de Mallorca, Sloper, 2014. Traducteur, prologue et notes : Juan José Delgado Gelabert

La familia de Germandre, Madrid, s.n., 1982. Traducteur : D. M.J.Q.

La familia de Germandre, Madrid, Centro general de administración, 1866. Traducteur : D. J.F. Saenz de Urraca

La familia de Germandre. Novela. Madrid, Imprenta de La Correspondencia de España, 1862.

Francisco el Expósito, Barcelona, Publicaciones Iberia, 1929, Traducteur : Augusto Riera.

Francisco, el expósito: novela de costumbres, Barcelona, Montaner y Simón, 1912. Traducteur : Juan B. Enseñat.

Francisco el inclusero. Comedia, Barcelona, Imprenta Viuda e Hijos de Mayol, 1850. Adaptateur : D. Francisco Luis de Ratés.

La hija natural, Madrid, Imprenta de Nieto y Cia, 1858. Traducteur : Joaquín María de Tejada. (Feuilleton de El Perú).

Historia de mi vida, Barcelona, Salvat, 1995. Traducteur : Joan T. Oliva.

Historia de mi vida, Paris, Librería Paul Ollendorf, 1909. Traducteur : Francisca A. de la Barella

Historia de mi vida, Madrid, Edaf, 1964. Traducteur : Isabel Azcoaga [réédition :1969]

Historia de mi vida, Barcelona, Parsifal, 1990. Traducteur : Joan T. Oliva

La historia del buen Simplón, León, Everest, 1991. Traducteur: Miguel Presa Pereira. Illustrateur : Gennadij Spiridin. D'après la version de $M^{a}$ Luise Völter [réédition : 1999].

Historia del verdadero garabato, Madrid, Altea, 1984, Traducteur : Ana Bermejo, Alberto Martín Baró. Illustrateur : Maurice Sand [rééd. 1986].

El hombre de nieve, Madrid, Administración, 1900.

Indiana, Barcelona, Editorial Mundial, 1929.

Indiana, La Editorial Artística Española, 1902. Traducteur: Francisco Casanovas, Illustrateur : Gaspar Campos. [rééd. 1906]

Indiana. Madrid, Calpe, 1888. Traducteur : Pedro Vauces. [rééd.1923.]

Indiana, Leya, Çaragoça, 1887. Traducteur : Eugenio de Ochoa.

Un invierno en Mallorca, Palma de Mallorca, Ingrama, 1997. Traducteur : B. Payeras.

Un invierno en Mallorca, Palma de Mallorca, Olañeta, 1997. Traducteur : Marcel Planas. Prologue : Robert Graves. [rééd. 2000]

Un invierno en Mallorca, Palma de Mallorca, Miquel Font, 1985. Traducteur : ? Prologue et notes : Valentí Puig.

Un invierno en Mallorca, Pollensa, P\&C Manus, 1991. Traducteur : Josep Moll Marquès. [rééd. 1998, 2001, 2003]

Un invierno en Mallorca, Palma de Mallorca, Bartolomé Rotger, 1902. Traducteur : Pedro Estelrich. Prologue : Gabriel Alomar.

Un invierno en Mallorca, Madrid, Espasa Calpe, 1934. Traducteur : Carmen Gallardo, viuda de Mesa.

Un invierno en Mallorca, Palma de Mallorca, Edit. Clumba, 1949. Traducteur: B. Payeras. Illustrateur : A. Sagristá. [réed. 1951, 1971, 1975] 
Un invierno en Mallorca, editorial Emegé, 1988.

Un invierno en Mallorca, Palma de Mallorca, Cort, 1999. Traducteur : ? [rééd. 2004]

Un invierno en Mallorca, Madrid, Edaf, 1990. Traducteur : Enrique Azcoaga. [rééd. 1974, 1978, 1971]

Un invierno en Mallorca, Barcelona, Ed. Mateu : Saturno, 1958. Traducteur : Tilo Casán.

Un invierno en Mallorca, Barcelona, RBA, 2009. Traducteur : Enrique Azcoaga. Prologue : Carme Riera. [rééd. 2010]

Un invierno en Mallorca, Barcelona, Orbis, 1989. Traducteur : Pedro Estelrich.

Un invierno en Mallorca, Palma de Mallorca, Luis Ripoll, 1974. Traducteur : Luis Ripoll. [rééd. 1983, 1995]

Un invierno en Mallorca, Palma de Mallorca,José Torns, 1932.

Jean de la Roche; François el Expósito, Madrid, Círculo de amigos de la Historia, 1972. [rééd. 1977]

Juan de la Roca, Madrid, El Cosmos, 1889. Traducteur : C. San Román.

Juan de la Roca : novela y cuentos, Madrid, Revista Literaria "Novela y cuentos", 1930.

Lavinia, Cáceres, Periférica, 2011. Traducteur: Manuel Arranz. Prologue: Manuel Arranz.

Leoni Leone; Mi secretario, Barcelona, Daniel Cortezo y Ca ${ }^{a}, 1888$. Traducteur : Eugenio de Ochoa. Illustrateur : J. Cabrinety.

El último amor, Barcelona, S. Aleu, 1884. Traducteur : S.A.R. Illustrateur : Mario.

Mallorca y Chopin en la «Historia de mi vida». Palma, Talleres Mossénalcover, 1951.

Traducteur : ?

La marquesa de Elmeval, Madrid, s.n., 1888. Traducteur :?

El marqués de Villamar, Barcelona, Ramón Sopena, 1967.

El Marqués de Villemer, Madrid, s. n., 1888. Traducteur : Joaquina Balmaseda.

El marqués de Villemer: una novela romántica completa, Madrid, Dédalo, 1940-44. Traducteur :???

El marqués de Villemer : comedia en cuatro actos y en prosa. Emp. Resumamos, Dumères, ? [Adaptation théâtrale]

El marqués de Villemer, Cádiz, s. n., 1863.

El marqués de Villemer, Madrid, Calpe, 1923. Traducteur : Emilio Daguerre.

El marqués de Villemer, Madrid, Revista Literaria "Novelas y cuentos", 1933.

Mauprat, Madrid, s.n., 1889.

Mauprat, Francisco el Expósito, Barcelona, Océano, 1982. Traducteur : Silvina Bullrich

Mi hermana Juana, Madrid, s. n., 1887. Traducteur : J. San Román.

Mont-Revêche, Madrid, s. n., 1859.

Pauline, Vilafranca del Penedés, Barcelona, Erasmus, 2009. Traducteur : Carlos Ezquerra.

La pequeña Fadette, Barcelona, Bruguera, 1982. Traducteur: Mª Elena de Salas, Illustrateur : JesúsGabán 

Amo [rééd. 2005] Urraca. Proa, 1999]

La reina Coax y otros relatos, Molins de Rei, Astri, 2000. Traducteur : María Cristina Davie. Prologue : Silvia Berlanga.

Los salvajes de París: relato de un viaje, Barcelona, Elba, 2011. Traducteur: Elisenda Julibert. Prologue : Roger Bartra.

El Secretario privado..., Nabupress, 2011.

El Secretario íntimo, Madrid, Establecimiento tipográfico de El Globo, 1876. Traducteur : Vizconde de San Javier.

Spiridion, Palma de Mallorca, Gabriel Quetglas Olin, 2008. Traducteur. Valeria Ciganda.

Los sueños de Simplón, Madrid, Gaviota, 1990. Traducteur : Elena del Amo. Illustrateur : Maurice Sand. [rééd. 2005]

Tamaris, Madrid, Libra, 1970.

Tamaris, Madrid, Club Internacional del Libro, 2009.

Tamaris, Madrid, Promoción y Ediciones, 1994.

Tamarís: novela de costumbres, Madrid, Centro general de administración, 1866. Traducteur : D. J. F. Saenz de Urraca.

¡Te amo! Novela, Barcelona, Librería Casazul, 193 ?.

El gigante Yeus in Tres cuentos de Francia, Madrid, Gaviota, 1991. Traducteur : Elena del

Valentina, Tortosa, Monclús, 1917. Traducteur : Francisco Iribarne.

Valvedre, Madrid, Centro general de administración, 1866. Traducteur : D. J. F. Saenzde

Viaje a través del cristal, Molins de Rei, Astri, 2000. Traducteur: María Cristina Davie. Prologue : Silvia Berlanga.

Viaje a través del cristal, Barcelona, Adiax, 1982.

La villa negra, Madrid, Imprenta de las Novedades, 1861. Traducteur: J. Trujillo (feuilleton de Las Novedades).

En las garras in XXVI Premio de Novela Corta "Gabriel Sijé", Alicante, Caja de Ahorros del Mediterráneo, 2002. Traducteur : Carmen Piña López-Yllana.

\section{En langue catalane :}

L'Estany del diable, Perpinyà, Proa, 1955. Traducteur : Just Cabot. [réédition : Barcelona,

La Fadeta, Lleida, Pagès Editors, 2006. Traductrice : Cristina Solé.

Història de la meva vida, Palma de Mallorca, Edicions UIB, 20009. Traductrice : Caterina Calafat ; Prologue : Carme Riera; Notes du texte : Brigitte Diaz.

La veritablehistòriad'enSucapà, Barcelona, Barcanova, 1991. Version de Maria Luise Völter ; version catalane de Joan Leita ; illustrations de Gennadi Spirin.

Un hivern a Mallorca, Barcelona, Edhasa, 1992. Traducteur : Marta Bes Oliva ; Prologue : Antoni Marí ; Épilogue : Robert Graves. [Réédition : 2009]

4 Un hivern a Mallorca, Barcelona, Proa, 1992. Traducteur: Marta Bes Oliva; Prologue : Antoni Marí ; Épilogue : Robert Graves. [Réédition : 2004, 2009] 
Un hivern a Mallorca, Mallorca, Moll, 1993. Traducteur, prologue, notes : Jaume Vidal Alcover.

Un hivern a Mallorca, Barcelona, Edicions 62, 2009. Traducteur : Marta Bes Oliva

Un hivern a Mallorca seguit de L'epistolari de la turista George Sand, Barcelona, Edicions de 1984, 2013. Traducteur, prologue, notes : Antoni-Lluc Ferrer

Ouvrages qui réécrivent l'épisode de George Sand à Majorque :

Gabriel Janer Manila, George, El perfum dels cedres, [Barcelona], Columna, 2002.

Miquel López Crespí, El Darrer hivern de Chopin i George Sand, Barcelona, Proa, 2004.

Llorenç Villalonga, Un estiu a Mallorca, Barcelona, Club Editor, 1975.

\section{NOTES}

1. Jean-François Botrel, «Traduire et transférer en Espagne à la fin du XIXe siècle » in Bulletin d'Histoire Contemporaine de l'Espagne: Transferts culturels : la traduction (XVIIIe-XXe siècles), no 49, pp. 63-72.

2. Ibid., p. 63.

3. Víctor Infantes, François Lopez et Jean-François Botrel (dir.), Historia de la edición y de la lectura en España 1472-1914, Madrid, Fundación Germán Sánchez Ruipérez, 2003.

4. Lola Jiménez, «La réception de l'œuvre d'Eugène Sue en Espagne » in Euvres et Critiques: la réception de la littérature populaire française en Espagne, XXXI, 2, Gunter Narr Verlag, Tübingen, 2006, pp. 47-65.

5. En 1822, l'écrivain et bibliophile Charles Nodier publia sa collection d' « anecdotes, narrations et contes sur les revenants, les spectres, les démons et les vampires » et l'intitula Infernaliana.

6. Juan Palomas, Victor Balaguer i Cirera, Renaixença, Revolució i Progrés, El Cap i la Nansa, Vilanova i la Geltrú, 2004, p. 42.

7. Maria Pilar Queralt, Balaguer, Edicions de Nou Art Thor (“Gent nostra"), Barcelona, 1984, p. 2.

8. Juan Palomas, op.cit., p. 58.

9. Ibid., p. 69.

10. Ibid., p. 234.

11. Àngels Santa, "Víctor Balaguer, traductor de George Sand" in Fco Lafarga \& Luis Pegenaute (eds), Traduccion y traductores, del Romanticismo al Realismo, Peter Lang, Bern, 2006, pp. 435-445.

12. Juan Palomas, op.cit., p. 68.

13. Àngels Santa, "Les avatars du Bossu de Paul Féval en Espagne" in Euvres et Critiques : La réception de la littérature populaire française en Espagne, XXXI,2, Gunter Narr Verlag, Tübingen, 2006, pp. 75-89.

14. Jean-René Aymes, "L'image de George Sand en Espagne (1836-1850) » in Jean-René AymesFernandez, L'image de la France en Espagne. 1808-1850, p. 247 [243-262].

15. Des études ont été faites à l'égard de cette période: Chantal Colonge, "George Sand en Espagne : ses traductions, ses lecteurs " in Claude Dumas (ed.), Culture et société en Espagne et en Amérique Latine au XIXe siècle, Lille, Université de Lille, 1980, p. 49-59. Francisco Lafarga, « Traducciones de G. Sand publicadas por Oliva (Barcelona, 1837-1838) », in George Sand, 1804-2004. 
L'île et la dame de Nohant, Estudi General Lul-lià, 2004, p. 209-215. Àngels Santa, « Víctor Balaguer, traductor de George Sand » in Traducción y traductores, del Romanticismo al Realismo, Bern, Peter Lang, 2006, p. 435-446.

16. En 1881-82 Valentine sera reprise par El País dans l'espace consacré au feuilleton, de même qu'en $1876 \mathrm{El}$ Orco et Marina. (Gisèle Cazottes, «Feuilletonistes à la mode et cosmopolitisme dans les quotidiens madrilènes sous Alphonse XII. Catalogue » in Iris, no 2, Montpellier, 1989, p. 2. Gisèle Cazottes, «À propos des écrivains à la mode dans la presse périodique madrilène sous Alphonse XII. Le nationalisme face au cosmopolitisme » in Iris, $n^{\circ}$ 1, Montpellier, 1989, p. 61).

17. Le Catálogo general de la Librería española e hispanoamericana ne débute qu'en 1901. Les études de Ferreres (Catálogo de novelas y novelistas españoles del siglo XIX, Madrid, Cátedra, 1979) et de Montesinos (Introducción a una historia de la novela en España en el siglo XIX, seguida del esbozo de una bibliografía española de traducciones de novelas 1800-1950, Madrid, Castalia, 1980) constituent des introductions au sujet mais ne rendent pas compte de la prolifique production éditoriale de l'époque.

18. Ibid., p. 53.

19. En 1864 il atteint les 20.000 exemplaires par jour et devient le plus vendu en Espagne.

20. «la représentante de toutes les médisances versées sur Majorque » (Un Hivern a Mallorca, Palma de Mallorca, Moll, 1993, p. 7. C'est nous qui traduisons).

21. Robert Graves, «George Sand en Mallorca » in George Sand, Un invierno en Mallorca, Palma de Mallorca, José J. Olañeta, 2000, p. 3. Texte repris et traduit au catalan pour l'édition de l'ouvrage chez Proa, 2004.

22. «Presentació» in Història de la meva vida, Palma, Edicions UIB, 2009, p. 7.[ «En reconnaissance à ses mérites en tant qu'écrivaine et intellectuelle, à la fois que célèbre devancière de la promotion de Majorque en Europe ». C'est nous qui traduisons.]

23. Ibid., p. 8. [« Les ouvrages de l'écrivaine qui sont le plus en rapport avec son séjour à Majorque en hiver 1838-39 ». C'est nous qui traduisons].

24. Ibid., p. 7.

25. George Sand, Correspondance générale, volume XIV, 12 avril 1857.

26. Benito Pérez Galdós, Tormento, Alicante, Biblioteca Virtual Miguel de Cervantes, 2000. En ligne: http://www.cervantesvirtual.com/nd/ark:/59851/bmc8w3b5 [Consulté le 24 novembre 2014]

27. Cf. Àngels Santa, La literatura popular francesa: folletines y melodramas, Lleida, Pagès Editors, 2012.

28. Plusieurs traités en témoignent depuis le domaine médical jusqu'au politique avec des noms célèbres tels que Floridablanca ou Jovellanos. (Bernabé Bartolomé Martínez, «La crianza y educación de los expósitos en España entre la Ilustración y el Romanticismo (1790-1835)" in Historia de la educación: Revista interuniversitaria, nº 10, 1991, p. 33-62.

29. La historia del buen simplón, Everest, 1999. Adaptateur: Maria Luise Völter. Los sueños de Simplón, Gaviota, 1990 [rééd. 2005]. Traducteur: Elena del Amo de la Iglesia. La veritable historia d'en Sucapà. Barcelona, Barcanova, 1991. Adaptateur: Maria Luise Völter. Traducteur: Joan Leita.

30. La veritable historia d'en Sucapà, op. cit., p. 9. [« Mais le mariage avec Monsieur le baron n'a pas été heureux. Aurore ayant perdu son mari, elle est partie pour Paris avec ses enfants ». C'est nous qui traduisons].

31. Ibid., p. 9 [«Elle a vécu très longtemps avec le compositeur Frédéric Chopin ». C'est nous qui traduisons].

32. Pour sa biographie voir Donald Allen Randolph, Eugenio de Ochoa y el romanticismo español, Berkeley and Los Angeles, University of California press, 1966.

33. Hortense DUFOUR, George Sand la somnambule, Paris, Ed. J'ai lu, 2004, p. 242.

34. Genoveva Elvira LOPEZ SANZ, «Romanticismo frente a clasicismo en El Artista (1835-1836) » en Espéculo. Revista de Estudios literarios, no 14, Madrid, [en ligne] [Consulté le 18 octobre 2014]. 
Disponible en :www.ucm.es/info/especulo/numero14/artista1.html

35. "El Romanticismo. ¡Cuántas ideas contrarias despierta esta palabra en la imaginación de los que la escuchan! Semejante a un mágico talismán, a unos halaga dulcemente como los acentos de una voz amada, como a una celeste armonía. Otros hay para quien la palabra romántico equivale a hereje[...] ¿Qué daños ha acarreado al mundo la escuela romántica? Escuela a que van enlazados los nombres de Homero, Dante, Calderón!..." (Cité par Genoveva Elvira López, op. cit., p. 3.)

36. Op. cit., p. 38.

37. «Collection de romans des plus célèbres auteurs étrangers ». C'est nous qui traduisons.

38. Borja Rodríguez Gutiérrez, « Noticias de la biblioteca Arte y letras (Barcelona 1881-1898) », in Cuadernos de Investigación Filología, 35-36 (2009-2010), p. 105-137.

39. Lídia Anoll, "El secretario íntimo" de George Sand, en la traducción del vizconde de San Javier (1876)", Alicante, Biblioteca Virtual Miguel de Cervantes, 2014. En ligne: http:// www.cervantesvirtual.com/nd/ark:/59851/bmch43k1. Consulté le 26 novembre 2014.

40. Dolores Thion Soriano-Mollá, “Joaquina García Balmaseda: una escritora isabelina al servicio de la mujer" in Anales, 23, 2011, p. 381-403.

41. Gérard Genette, Seuils, Paris, Seuil, 2002, p. 7.

42. Le terme, dérivé de porc (cochon) s'applique aux actes relevant d'une connotation de saleté, trait attribué à cet animal. En conséquence il peut être employé pour porter allusion aux actes en rapport avec la sexualité.

43. George Sand, Història de la meva vida, Palma de Mallorca, Edicions UIB, 2009. p. 18.

44. C'est le cas de Francisco el Expósito dont le protagoniste, dans l'édition de 1912, conforme au «Nihil obstat» de la censure, est présenté comme un exemple moral à suivre tel qu'en témoignent des illustrations qui montrent l'éducation d'un enfant vertueux.

\section{ABSTRACTS}

The history of the modern Spanish novel has proved that the character of this country is thinly present at the beginning of the genre. During the first-half of the XIX century translations, and even imitations, occupy an important place at the expense of the national production, according to José $F$. Montesinos. Regarding to this fact, the French letters influence on Spanish publishing activity is strong. The present study aims to continue the approach initiated by this critic from the date he left it (1850) until nowadays. Taking to account the magnitude of the study, this article focuses on two writers, Paul Féval and George Sand, which got the Spanish favor at the same time that they reached the success in France, and whose vogue continued along the 20th century owing to the particular historical facts lived by Spain. This paper showcases the reception and acculturation phenomena between the both sides of Pyrenees.

L'histoire du roman espagnol moderne a prouvé que le génie de ce pays est peu présent dans les débuts du genre. Pendant la première moitié du XIXe siècle les traductions et éventuellement les imitations occupent une place prédominante au détriment de la production nationale, d'après les thèses avisées de José F. Montesinos. À cet égard, l'influence des lettres françaises sur l'activité éditoriale espagnole est fort remarquable. Cette analyse a pour but de poursuivre le travail entamé par ce critique à la date qu'il prend comme limite (1850) et de le poursuivre jusqu'à nos jours. Vu l'envergure de l'étude, l'article focalise l'attention sur deux écrivains, Paul Féval et George Sand, qui obtinrent la faveur du lectorat espagnol parallèlement au succès acquis en 
France et dont la vogue se poursuivit le long du XXe siècle à cause du devenir historique particulier de l'Espagne. Le travail permettra donc d'envisager des phénomènes de réception et d'acculturation entre la création des deux côtés des Pyrénées.

\section{INDEX}

Keywords: Paul Féval, George Sand, Spain, translation, reception, acculturation

Mots-clés: Paul Féval, George Sand, Espagne, traductions, réception, acculturation

\section{AUTHORS}

\section{ÀNGELS SANTA}

Professeure de littérature française à l'Université de Lleida en Catalogne (Espagne). Elle y dirige un groupe de recherches sur la Littérature populaire française et la culture médiatique. Sa recherche porte aussi sur l'écriture féminine et autobiographique à l'époque contemporaine que sur la littérature comparée (française-espagnole-catalane). Parmi ses dernières publications, on peut signaler : Des lettres et des femmes... La femme face aux défis de l'histoire (Peter Lang, 2013), "L'évolution de Mme de Fontanin pendant la première guerre mondiale » in Cahiers Roger Martin du Gard, n8 : Écritures de la guerre (Gallimard, 2014) et « Politique au féminin : le cas de George Sand » in De l'ordre et de l'aventure. Langue, littérature, francophonie. Hommage à Giovanni Dotoli (Hermann, 2014). Elle dirige la revue d'études de langue et de littérature françaises et francophones L'Ull crític. Elle a réalisé l'édition critique de Jacques de George Sand dans les Euvres complètes publiées par Champion sous la direction de Béatrice Didier, sortie en 2012.

\section{CARME FIGUEROLA}

Profesora Titular à l'Université de Lleida, elle y enseigne la langue et la littérature françaises. Son activité de recherche porte sur plusieurs intellectuels de la période d'entre-deux-guerres tels que Roger Martin du Gard, Georges Duhamel, Paul Nizan, Eugène Dabit ou Jean-Richard Bloch. Un deuxième volet vise les aspects de la réception littéraire et culturelle dans le domaine francocatalan-espagnol où elle se centre sur l'influence que des écrivains français ont exercée sur leurs homologues espagnols (Narcís Oller, Pérez Galdós, Pardo Bazán). Le troisième axe qui attire son attention est centré sur le phénomène de la littérature populaire où elle s'est occupée d'auteurs tels que Jules Verne ou Michel Zévaco. Actuellement elle focalise ses efforts sur la littérature féminine, ce qui lui a permis d'aborder des écrivaines françaises et francophones, à savoir, George Sand, Delly, Irène Némirovsky, Maïssa Bey et Malika Mokeddem essentiellement. 